\title{
Maternal group B Streptococcus recto vaginal colonization increases the odds of stillbirth: evidence from Eastern Ethiopia
}

Tesfaye Assebe Yadeta ${ }^{1,3,4^{*}}$, Alemayehu Worku², Gudina Egata ${ }^{3}$, Berhanu Seyoum ${ }^{4}$, Dadi Marami ${ }^{4}$ and Yemane Berhane ${ }^{5}$

\begin{abstract}
Background: Group B Streptococcus (GBS) causes a significant number of stillbirths. Despite this, there is little documented information on the association between stillbirth and pregnant women's GBS recto vaginal colonization in Sub Saharan Africa. As such, this study was aimed at identifying the association between stillbirth and pregnant women's GBS recto vaginal colonization in Eastern Ethiopia.

Methods: A health facility-based cross-sectional study was conducted among 1688 pregnant women who came for delivery service in Harar town, Eastern Ethiopia between June to October in 2016. Data were collected using a pre-tested structured questionnaire and checklist (which utilize clinical record). Group B streptococcus positivity of the pregnant women was confirmed by culture of recto vaginal swab using selective media. The association between GBS colonization and stillbirth was examined using multivariable logistic regression analysis. A statistical significance was declared at $p$-value $\leq 0.05$.

Results: Of the 1688 pregnant women who participated in the study, 144 had stillbirths, representing a prevalence of $8.53 \%$ [(95\% Cl: $(7.19,9.86)]$. Group B Streptococcus colonization at birth was detected in 231 women (13.68\%; $95 \% \mathrm{Cl} 12.04,15.32)$. Of these 144 stillbirths 59 (40.97\%) were from colonized mothers and $72(59.03 \%)$ were from non-colonized mothers. Of these 59 stillbirth from colonized mothers, 32(54.23\%) were intrapartum stillbirth, 27(45.77\%) were antepartum stillbirth occur before exposed to intrapartum antibiotic prophylaxis (IAP). After controlling for potential confounders, the odds of having a stillbirth were 8.93 times higher among recto vaginal GBS colonized pregnant women $[\mathrm{AOR}=8.93 ; 95 \% \mathrm{Cl} ;(5.47,14.56)]$.

Conclusions: This study demonstrated a significant association between maternal recto vaginal GBS colonization and stillbirth. Efforts to reduce stillbirth need to consider prevention of GBS colonization among pregnant women. Maternal vaccination may provide a feasible strategy to reduce stillbirth due to GBS.
\end{abstract}

Keywords: Stillbirth, GBS, Maternal recto vaginal colonization, Harar, Ethiopia

\section{Background}

The prevention of stillbirth remains a major global challenge. Of the estimated 2.6 million stillbirths that occur globally every year, 98\% occur in low-income and middle-income countries [1]. Efforts to reduce stillbirths in low-income countries have not shown much progress.

\footnotetext{
* Correspondence: tesfaye.assebe@yahoo.com

${ }^{1}$ School of Nursing and Midwifery, College of Health and Medical Sciences, Haramaya University, Harar, Ethiopia

${ }^{3}$ School of Public Health, College of Health and Medical Sciences, Haramaya University, Harar, Ethiopia

Full list of author information is available at the end of the article
}

Sub-Saharan Africa harbors the highest stillbirth rates with Ethiopia ranking fifth among the ten countries with the highest stillbirth rates in the world [1,2].

Stillbirth is a major cause of psychosocial distress, grief and guilt to families [3]. In Sub Saharan Africa, mothers who have stillbirth are often subjected to severe psychosocial pressure; especially women who experience repeated stillbirth, can be out casted, dishonored and subjected to divorce $[4,5]$.

The causes of stillbirth vary greatly from country to country. In low income countries about one-third of all

(c) The Author(s). 2018 Open Access This article is distributed under the terms of the Creative Commons Attribution 4.0 International License (http://creativecommons.org/licenses/by/4.0/), which permits unrestricted use, distribution, and 
stillbirths are attributed to maternal infection during pregnancy [6]. Group B Streptococcus colonization and vertical transmission can cause fetal infection and stillbirth as a direct result of toxin-induced cytolysis [7, 8]. Group B Streptococcus is estimated to account for $15 \%$ of all infection related stillbirths globally [9] and Africa harbor $73.68 \%$ of the estimated GBS caused stillbirth [10]. Other factors associated with stillbirth include: higher maternal age, residence, lower economic status, lower education level, poor antenatal care (ANC) uptake, antepartum hemorrhage, essential hypertension, pre-eclampsia, obstetric complication during labour, preterm delivery, low birth weight, and fetal mal-presentation [11, 12].

Stillbirths due to GBS are preventable $[9,13]$. However, most of Sub-Saharan African countries do not have guidelines for the prevention of GBS infection, which could increase associated health risks to the mother and fetus [14]. The inaction could be related to a lack of evidence from the region. As such, this study assessed the association between GBS colonization and stillbirth in Eastern Ethiopia.

\section{Methods}

\section{Study setting}

This study was performed in three health facilities (Hiwot Fana Specialized University Hospital, Jugal Hospital and Arategna Health Center) in Harar town, Eastern Ethiopia. Harar is located $510 \mathrm{~km}$ east of the capital city of Ethiopia, Addis Ababa. Ethiopia is a low-income country with a total fertility rate of 4.6 per woman [15], stillbirth rates of 25.5 per 1000 birth [11], a neonatal mortality rate of 29 per 1000 live births [15] and 34.3\% of neonatal deaths are due to infection [16].

\section{Study design and sampling}

A cross-sectional study was done between June and October 2016. The study participants were pregnant women came for delivery services at labour and delivery rooms of the selected health facilities. This study is part of a larger study conducted to assess GBS colonization among a total of 1688 singltone pregnant women. Women who recieved antibiotics in the last 2 weeks during their pregnancy prior to specimen collection and women who came due to vaginal bleeding prior to labour began, were excluded from this study [17, 18]. Study participants were taken proportional to the client load of the selected health facilities.

\section{Data collection}

Data were collected using a pretested and structured questionnaire. In addition, a checklist was used to extract data from the medical record, and a laboratory test was performed to detect GBS colonization from a recto-vaginal swab. The data collection tools were developed by reviewing previous related data collection instruments $[15,19]$. The original questionnaire was prepared in English language and later translated into the local languages (Amharic and Afan Oromo) for data collection. Forward and backward translations were performed by language experts.

A six-day training was given to attending midwives and the supervisors who worked as data collectors. The training for data collectors and supervisors addressed issues related to data collection procedures and tools, interviewing techniques, medical record review and specimen collection procedures. Two medical microbiologists were read, confirm and interpret laboratory test results. Three medical laboratory technologists involved in media preparation and sterilization processes. A research manual was prepared to guide training, data collection and management.

\section{Measurement}

Stillbirth was the dependent variable in this study and this information was obtained from medical records. It was labelled as "yes" and "no" with a code of 1 and 0 , respectively. ANC follow-up, hypertensive disease, women's GBS test result, prolonged labour, birth weight and gestational age were independent variables.

Age of the mother was documented based on maternal reply and later grouped as 15-19, 20-24, 25-29 and 3034 and $35+$ with code $1,2,3,4$ and 5 , respectively for analysis. Maternal education was grouped as "literate" for those who could read and write and all others as "illiterate" and was coded 0 and 1, respectively. Number of births (parity) were grouped as one primiparity (one delivery), multiparous (2-4 delivery) and grand multiparous ( $\geq 5$ deliveries) and code with 1,2 and 3, respectively [20]. To determine the economic status of the families, wealth index was used. The wealth distribution was generated by applying principal components analysis to 33 household variables. The wealth status was determined by using three groups, poor as 1 , middle as 2 , and better as 3 [21].

Hypertesive disease and prolonged labour were obtained from the medical record and labeled as "yes" and "no" and coded with 1 and 0 , respectively. Birth weight was categorized as $<2500 \mathrm{~g}$ and $\geq 2500 \mathrm{~g}$ and labeled as "yes" and "no" and code with 1 and 0 , respectively. Similarly, gestational age was categorized as $<37$ weeks and $\geq 37$ weeks and labeled as "yes" and "no" and code with 1 and 0 , respectively.

The specimens were collected by the attending midwives from the lower third of the vagina and rectum of women using a sterile cotton applicator. The specimens collection were performed at admission to the labour and delivery room of the selected health facilities. The laboratory procedure was done following the Center for Disease Control and Prevention (CDC) recommendation 
and Standard Operating Procedures described elsewhere $[22,23]$. Details of specimen transportation and processing have been published previously [24]. A positive GBS reading was labeled as "yes" and a negative reading was labeled as "no".

\section{Statistical analysis}

Initially crude odds ratio (COR) along with 95\% confidence interval was estimated to assess the association between each independent variable and the outcome variable. Variables with $p$-value $\leq 0.20$ in the bivariable analyses were considered in the multivariable logistic regression model. Important variables deemed to be considered were also included, though they did not reach a $p$-value less than 0.20 . Multicollinearity was tested using the Variance Inflation Factor (VIF) test, the tolerance test and values of the standard error. No multicollinearity problem was found. Correlation matrix and covariate matrix were tested for the final model. The final model selections were performed by: log likelihood ratio test, Akaike's information criterion, and Bayesian information criterion. The Hosmer-Lemeshow goodness-of-fit tests were used to test for model fitness [25]. The logistic regression model was used to assess the association between women's GBS recto vaginal colonization and the outcome variable (stillbirth) by controlling for other potential confounding variables. Adjusted Odds Ratio (AOR) along with 95\% confidence interval was estimated to assess the strength of the association. Statistical significance was declared at a $p$-value $\leq 0.05$.

\section{Ethical approval and consent to participate}

The study material was reviewed and approved by the Institutional Health Research Ethics Review Committee of the College of Health and Medical Sciences at Haramaya University. permission was obtained from each of the health facilities involved in the study. Women detected to have GBS colonization were provided antibiotic prophylaxis and women who had a stillbirth received counseling. Neonates with health problems were treated and immediate referral was also facilitated.

\section{Results}

The study enrolled a total of 1688 pregnant women. The age of participants ranged from 15 to 46 years with the mean (standard deviation) of 26.59 ( \pm 5.63 ) years. Almost all $(95.73 \%)$ of the participants were married, $47.04 \%$ had no formal education, and $44.14 \%$ were rural residents (Table 1). A large proportion (33.23\%) of the pregnant women had never attended ANC at a health facility. The mean number of deliveries was 2.6 (with a range from 1 to 14). About $11 \%$ of pregnant women had experienced hypertension, $23.22 \%$ had experienced prolonged labour, and $15.26 \%$ had low birth weight. Group
Table 1 Socio-demographic characteristics of the study participants Harar town, Eastern Ethiopia, 2016

\begin{tabular}{|c|c|c|}
\hline Characteristics & Frequency $(n)$ & Percent (\%) \\
\hline \multicolumn{3}{|l|}{ Residence of mothers } \\
\hline Urban & 943 & 55.86 \\
\hline Rural & 745 & 44.14 \\
\hline \multicolumn{3}{|l|}{ Age of mothers in year } \\
\hline$\leq 19$ & 301 & 17.83 \\
\hline $20-24$ & 510 & 30.21 \\
\hline $25-29$ & 461 & 27.31 \\
\hline $30-34$ & 275 & 16.29 \\
\hline$\geq 35$ & 141 & 8.35 \\
\hline \multicolumn{3}{|l|}{ Ethnicity } \\
\hline Oromo & 1214 & 71.92 \\
\hline Amhara & 267 & 15.82 \\
\hline Harari & 95 & 5.63 \\
\hline Somali & 15 & 0.89 \\
\hline Other $^{\mathrm{a}}$ & 97 & 5.75 \\
\hline \multicolumn{3}{|l|}{ Religion } \\
\hline Muslim & 1286 & 76.18 \\
\hline Orthodox christian & 308 & 18.25 \\
\hline Protestant & 89 & 5.27 \\
\hline Catholic & 5 & 0.3 \\
\hline \multicolumn{3}{|l|}{ Marital status } \\
\hline Married & 1616 & 95.73 \\
\hline Others $^{b}$ & 72 & 4.27 \\
\hline \multicolumn{3}{|l|}{ Educational status } \\
\hline Literate & 894 & 52.96 \\
\hline Illiterate & 794 & 47.04 \\
\hline
\end{tabular}

Others $^{\mathrm{a}}$ Gurage, Tigre, Silte,...; others ${ }^{\mathrm{b}}$ single, separated, divorced, widowed

B Streptococcus colonization at birth was detected in 231 (13.68\%; 95\% CI 12.04, 15.32) (Table 2).

The overall, 144 had stillbirths, representing a proportion of $8.53 \%$ [ $(95 \%$ CI: $(7.19,9.86)]$. Of these 144 stillbirths 59 (40.97\%) were from colonized mothers, $72(59.03 \%)$ were from non-colonized mothers. Of these 59 stillbirth from colonized mothers, 32(54.23\%) were intrapartum stillbirth, 27(45.77\%) were antepartum stillbirth occur before exposed to IAP (Table 3).

The multivariable logistic regression analysis revealed the odds of stillbirth was 8.93 times higher among recto vaginal GBS colonized pregnant women compared to those who had no colonization $[\mathrm{AOR}=$ 8.93; 95\% CI; $(5.47,14.56)]$. In addition, the odds for pregnant women who attended ANC follow-up was lower by $47 \%$ [AOR $=0.53 ; 95 \% \mathrm{CI} ;(0.34,0.82)]$. The odds for pregnant women with hypertensive disorders was $\mathrm{AOR}=4.66$; $95 \% \mathrm{CI} ;(2.77,7.8)$, for those with prolonged labor was $\mathrm{AOR}=3.65$; $95 \% \mathrm{CI}$ : $(2.38,5.60)$, for 
Table 2 Pregnancy, labour, and delivery related characteristics of the study participants Harar town, Eastern Ethiopia, 2016

\begin{tabular}{|c|c|c|}
\hline Characteristics & Frequency $(n)$ & Percent (\%) \\
\hline \multicolumn{3}{|l|}{ Para } \\
\hline 1 & 722 & 42.77 \\
\hline $2-4$ & 755 & 44.73 \\
\hline$\geq 5$ & 211 & 12.50 \\
\hline \multicolumn{3}{|l|}{ ANC follow up } \\
\hline No & 561 & 33.23 \\
\hline Yes & 1127 & 66.77 \\
\hline \multicolumn{3}{|l|}{ Anemia } \\
\hline No & 1535 & 90.94 \\
\hline Yes & 153 & 9.06 \\
\hline \multicolumn{3}{|c|}{ Hypertensive disease } \\
\hline No & 1502 & 88.98 \\
\hline Yes & 186 & 11.02 \\
\hline \multicolumn{3}{|c|}{ Prolonged labour } \\
\hline No & 1296 & 76.78 \\
\hline Yes & 392 & 23.22 \\
\hline \multicolumn{3}{|l|}{ Birth weight } \\
\hline$\geq 2500 \mathrm{~g}$ & 1422 & 84.24 \\
\hline$<2500 \mathrm{~g}$ & 266 & 15.76 \\
\hline \multicolumn{3}{|l|}{ Gestational age } \\
\hline$\geq 37$ weeks & 1540 & 91.23 \\
\hline$<37$ weeks & 148 & 8.77 \\
\hline \multicolumn{3}{|l|}{ GBS test result } \\
\hline Negative & 231 & 13.68 \\
\hline Positive & 1457 & 86.32 \\
\hline \multicolumn{3}{|l|}{ IAP received } \\
\hline No & 964 & 57.11 \\
\hline Yes & 724 & 42.89 \\
\hline
\end{tabular}

IAP intrapartum antibiotic prophylaxis

those with low birth weight was $\mathrm{AOR}=1.81 ; 95 \% \mathrm{CI}$ : $(1.09,3.03)$, and preterm delivery $\mathrm{AOR}=4.24 ; 95 \% \mathrm{CI}$ : $(2.41,7.45)$ (Table 3$)$.

\section{Discussion}

This study showed a strong association between stillbirths and maternal GBS colonization, even after controlling for other potential confounders. Other studies have also reported similar findings [26, 27]. It is evident that GBS cytolysis breaches maternal-fetal barriers ultimately causing intrauterine fetal death [7]. The stillbirths due to recto vaginal colonization of pregnant women are due to ascending infection. The genome sequencing studies have demonstrated the GBS isolated at birth from the skin of newborns were genetically identical to maternal GBS colonizing isolates [26].
Intrapartum antibiotic prophylaxis is highly effective in preventing newborn's GBS colonization [28]. However, there are limitations in the clinical benefit of IAP in reducing stillbirth. Antibiotics, for prophylaxis must be administered before the potential exposure, but stillbirth may occur before labour started [29]. In this study, $45.77 \%$ of stillbirths occurred before labour began.

Furthermore, identifying pregnant women who need IAP has been challenging for lower- and middle-income countries since most pregnant women did not attend ANC and most deliveries occur at home [30]. However, recent achievements in increasing coverage for the ANC and institutional/ facility delivery could improve the possibility of introducing screening, prevention and treatment interventions in routine ANC and delivery services.

Maternal vaccination could also be cost-effective to prevention programs since it can induce population-level herd immunity, address limitations in the clinical benefit of IAP in reducing stillbirth and late onset of neonatal GBS disease [31, 32]. Maternal immunization could protect the infant and fetus from invasive GBS disease. A clinical trials study, in South Africa, evaluated GBS polysaccharide-protein conjugate vaccine among pregnant women. The vaccine was well tolerated, had similar safety profiles with placebo, and induced capsular-specific antibody responses, in a women. Infant born from vaccinated pregnant women, resulted in higher GBS serotype-specific antibody concentrations $[31,33]$.

The burden of stillbirth on families, especially women, is severe and long lasting, yet stigma and taboo hinder this burden even in high-income countries. Mothers may be unlikely to seek medical care and such stillbirths could go unreported, thereby skewing or minimizing the actual reported cases of stillbirth [34]. Since women coming to health facilities for delivery could be those with better access to health services and perhaps more aware of the benefits of seeking health services for improved newborn health, the occurrence of stillbirth is likely to be an underestimation. One could also argue those women who opted for institutional delivery could be those with health problems the reported stillbirth represents an overestimation.

Antenatal care follow up was one of the predictors' of stillbirth. Similar findings were reported in other studies conducted in different part of the world [11,35]. Despite this, ANC follow up was a protective for GBS related stillbirth. Only $32 \%$ of pregnant women had four recommended ANC visits in Ethiopia [15]. To achieve the sustainable development goal to end all preventable stillbirth and neonatal mortality, health promotion programs must better target those communities where maternal health care utilization is low. Urgent effective interventions are therefore needed to improve the ANC coverage as part of a stillbirth and neonatal reduction strategy. 
Table 3 Factors associated with stillbirth among pregnant women, Harar, Eastern Ethiopia, 2016

\begin{tabular}{|c|c|c|c|c|c|c|c|c|}
\hline \multirow[t]{2}{*}{ Characteristics } & \multirow{2}{*}{$\begin{array}{l}\text { Stillbirth } \\
n=144(\%)\end{array}$} & \multirow{2}{*}{$\begin{array}{l}\text { Live birth } \\
n=1544(\%)\end{array}$} & \multicolumn{3}{|c|}{ Crude OR } & \multicolumn{3}{|c|}{ Adjusted OR } \\
\hline & & & $\mathrm{OR}$ & $95 \% \mathrm{C}$ & & $\mathrm{OR}$ & $95 \%$ & \\
\hline \multicolumn{9}{|l|}{ GBS colonization } \\
\hline No & 5.83 & 94.17 & 1 & & & 1 & & \\
\hline Yes & 25.54 & 74.46 & 5.53 & 3.83 & 7.99 & $8.93^{* * *}$ & 5.47 & 14.56 \\
\hline \multicolumn{9}{|l|}{ ANC follow up } \\
\hline No & 15.15 & 84.85 & 1 & & & 1 & & \\
\hline Yes & 5.24 & 94.76 & 0.3 & 0.21 & 0.43 & $0.53^{* *}$ & 0.34 & 0.82 \\
\hline \multicolumn{9}{|l|}{ Anemia } \\
\hline No & 7.88 & 92.12 & 1 & & & 1 & & \\
\hline Yes & 15.03 & 84.97 & 2.06 & 1.27 & 3.34 & 0.79 & 0.42 & 1.45 \\
\hline \multicolumn{9}{|c|}{ Hypertensive disorder } \\
\hline No & 6.32 & 93.68 & 1 & & & 1 & & \\
\hline Yes & 26.34 & 73.66 & 5.29 & 3.59 & 7.79 & $4.66^{* * *}$ & 2.77 & 7.84 \\
\hline \multicolumn{9}{|c|}{ Prolonged labour } \\
\hline No & 6.10 & 93.90 & 1 & & & 1 & & \\
\hline Yes & 16.58 & 83.42 & 3.06 & 2.15 & 4.34 & $3.65^{* * *}$ & 2.38 & 5.60 \\
\hline \multicolumn{9}{|l|}{ Para } \\
\hline 1 & 8.17 & 91.83 & 1 & & & 1 & & \\
\hline $2-4$ & 8.21 & 91.79 & 1.00 & 0.69 & 1.45 & 1.46 & 0.88 & 2.42 \\
\hline$\geq 5$ & 10.90 & 89.10 & 1.31 & 0.82 & 2.28 & 1.29 & 0.58 & 2.92 \\
\hline \multicolumn{9}{|l|}{ Age of women } \\
\hline$\leq 19$ & 10.63 & 89.37 & 1 & & & 1 & & \\
\hline $20-24$ & 6.86 & 93.14 & 0.6 & 0.37 & 1.02 & 1.11 & 0.60 & 2.05 \\
\hline $25-29$ & 9.33 & 90.67 & 0.86 & 0.53 & 1.4 & 1.10 & 0.58 & 2.11 \\
\hline $30-34$ & 5.82 & 94.18 & 0.51 & 0.27 & 0.96 & 0.42 & 0.19 & 0.95 \\
\hline$\geq 35$ & 12.77 & 87.23 & 1.23 & 0.66 & 2.27 & 0.76 & 0.30 & 1.92 \\
\hline \multicolumn{9}{|l|}{ Resident } \\
\hline Urban & 5.20 & 94.80 & 1 & & & 1 & & \\
\hline Rural & 12.75 & 87.25 & 2.66 & 1.86 & 3.81 & 1.27 & 0.69 & 2.33 \\
\hline \multicolumn{9}{|c|}{ Educational status } \\
\hline literate & 6.26 & 93.74 & 1 & & & 1 & & \\
\hline illiterate & 11.08 & 88.92 & 1.86 & 1.31 & 2.64 & 1.13 & 0.69 & 1.83 \\
\hline \multicolumn{9}{|l|}{ Wealth status } \\
\hline Poor & 14.03 & 85.97 & 1 & & & 1 & & \\
\hline Middle & 7.00 & 93.00 & 0.46 & .30 & 0.68 & 1.06 & 0.58 & 1.91 \\
\hline Better & 4.45 & 95.55 & 0.28 & 0.17 & 0.45 & 0.65 & 0.29 & 1.44 \\
\hline \multicolumn{9}{|l|}{ Birth weight } \\
\hline$\geq 2500 \mathrm{~g}$ & 5.98 & 94.02 & 1 & & & 1 & & \\
\hline$<2500 \mathrm{~g}$ & 22.18 & 77.82 & 4.48 & 3.11 & 6.44 & $1.81^{*}$ & 1.09 & 3.03 \\
\hline \multicolumn{9}{|l|}{ Gestational age } \\
\hline$\geq 37$ weeks & 5.97 & 94.03 & 1 & & & 1 & & \\
\hline$<37$ weeks & 35.14 & 64.86 & 8.52 & 5.72 & 12.69 & $4.24^{* * *}$ & 2.41 & 7.45 \\
\hline \multicolumn{9}{|l|}{ IAP received } \\
\hline No & 7.37 & 92.63 & 1 & & & 1 & & \\
\hline Yes & 8.53 & 91.47 & 1.41 & 1.00 & 1.98 & 1.01 & 0.67 & 1.51 \\
\hline
\end{tabular}

IAP intrapartum antibiotic prophylaxis, $O R$ odds ratio, $\mathrm{Cl}$ confidence intervals; ${ }^{*}=p, 0.05 ;{ }^{* *}=p, 0.01 ;{ }^{* * *}=p, 0.001$ 
In this study preterm is significantly associated with stillbirth, and this was consistent with previous study [35]. Furthermore, GBS ascending infection, resulting in infection of fetal membranes, decidua and fetus, causing premature rupture of the membrane. Prolonged exposure of the fetus to maternal bacterial flora without any protective membrane barrier enhances the transmission. Host inflammatory response stimulation of prostaglandin and protease synthesis are increases uterine contractility and results in preterm delivery [36]. Vascular insufficiency in pre-eclampsia reduces blood flow to the placenta, leading to hypoxia of the fetus which may also be associated with stillbirth [37, 38]. In prolonged labour, there is also an increased chance that a fetus will suffer from asphyxia due to umbilical cord compression, placental abruption, maternal low blood pressure and birth trauma. Problems with the placenta pose risks to the fetus, including lack of oxygen and nutrients, which can impair fetal growth and could also lead to low birth weight and preterm delivery $[12,39]$.

The strengths of this study were that a relatively high number of participants included and the study obtained swab samples from both the rectum and vagina, which help to improve the yield [40]. All swabs were transported in Amie's transport media to the Medical Microbiology Laboratory within $4 \mathrm{~h}$ of collection [41]. Selective and differential media were used to isolate and GBS [23].

Measurement and diagnostic biases were minimized by assigning two medical microbiology experts to measure and read the results. Thus, the procedures used was believed to help to reasonably estimate the association. As limitations, the data obtained from the medical records may be potential sources of biases. This has been minimized through verifying the data by the study team before discharging the mother and newborn. Moreover, collecting of microbiological evidence of invasive GBS infection from a normally sterile site, such as fetal blood from the umbilical cord or from the heart, lung aspirate, cerebrospinal fluid or fetal tissues as recommended [42] were not done due to resource constraints. Moreover, immunologic and placenta investigations were also not possible in this setting. Finally, unaccounted and residual confounding could have had an effect on the association found [43, 44].

\section{Conclusions}

This study identified a strong association between maternal recto vaginal colonization of GBS and stillbirth. Efforts to reduce stillbirth need to consider prevention of colonization by GBS among pregnant women. Further stillbirth reduction efforts need to consider introducing effective prevention strategies and improving the quality of the ANC and intrapartum care. Maternal vaccination may provide feasible strategy to reduce stillbirth due to GBS.

\section{Abbreviations}

ANC: Antenatal care; CDC: Center of disease control and prevention; GBS: Group B streptococcus; IAP: Intrapartum antibiotic prophylaxis; LMICS: Low-and-middle income countries; SDG: Sustainable development goal; SOPS: Standard Operating Procedures

\section{Acknowledgements}

The authors would like to thank Haramaya University for financial support, Addis Continental Institute of Public Health for technical support, the study participants, data collectors, and staff of the Department of Medical

Laboratory Sciences, College of Health and Medical Sciences for their kind cooperation.

\section{Funding}

This study was financially supported by Haramaya University.

\section{Availability of data and materials}

The datasets used and/or analyzed during the current study are available from the corresponding author on reasonable request.

\section{Authors' contributions}

TA, AW, GE, BS and YB conceived and designed the paper, involved in data collection, performed the statistical analysis, interpret the results, wrote and reviewed the manuscript. DM interprets the result, wrote and reviewed the manuscript. All authors read and approved the final version of manuscript before submission.

\section{Ethics approval and consent to participate}

The written consent was obtained from each respondent. If the respondent was under 18 years old, in addition to their assent, then consent was sought from her husband, parents or guardian. Privacy and confidentiality were resolutely kept in all data collection procedures. The study material was reviewed and approved by the Institutional Health Research Ethics Review Committee of the College of Health and Medical Sciences at Haramaya University. Permission was obtained from each of the health facilities involved in the study.

\section{Consent for publication}

Not applicable.

\section{Competing interests}

The authors declare that they have no competing interests.

\section{Publisher's Note}

Springer Nature remains neutral with regard to jurisdictional claims in published maps and institutional affiliations.

\section{Author details}

${ }^{1}$ School of Nursing and Midwifery, College of Health and Medical Sciences, Haramaya University, Harar, Ethiopia. ${ }^{2}$ Department of Epidemiology and Biostatistics, School of Public Health, Addis Ababa University, Addis Ababa, Ethiopia. ${ }^{3}$ School of Public Health, College of Health and Medical Sciences, Haramaya University, Harar, Ethiopia. ${ }^{4}$ Department of Medical Laboratory Sciences, College of Health and Medical Sciences, Haramaya University, Harar, Ethiopia. ${ }^{5}$ Department of Epidemiology, Addis Continental Institute of Public Health, Addis Ababa, Ethiopia.

Received: 24 April 2018 Accepted: 5 October 2018

Published online: 19 October 2018

\section{References}

1. Lawn JE, Blencowe H, Waiswa P, Amouzou A, Mathers C, Hogan D, Flenady V, Frøen JF, Qureshi ZU, Calderwood C. Stillbirths: rates, risk factors, and acceleration towards 2030. Lancet. 2016;387(10018):587-603.

2. Wang $H$, Bhutta ZA, Coates MM, Coggeshall M, Dandona L, Diallo K, Franca EB, Fraser M, Fullman N, Gething PW. Global, regional, national, and selected subnational levels of stillbirths, neonatal, infant, and under-5 mortality, 19802015: a systematic analysis for the Global Burden of Disease Study 2015. Lancet. 2016;388(10053):1725 
3. Gopichandran V, Subramaniam S, Kalsingh MJ. Psycho-social impact of stillbirths on women and their families in Tamil Nadu, India-a qualitative study. BMC pregnancy and childbirth. 2018;18(1):109.

4. Kiguli J, Namusoko S, Kerber K, Peterson S, Waiswa P. Weeping in silence: community experiences of stillbirths in rural eastern Uganda. Glob Health Action. 2015:8(1):24011.

5. Sisay MM, Yirgu R, Gobezayehu AG, Sibley LM. A qualitative study of attitudes and values surrounding stillbirth and neonatal mortality among grandmothers, mothers, and unmarried girls in rural Amhara and Oromiya regions, Ethiopia: unheard souls in the backyard. Journal of Midwifery \& Women's Health. 2014;59(s1).

6. Engmann C, Garces A, Jehan I, Ditekemena J, Phiri M, Mazariegos M, Chomba E, Pasha O, Tshefu A, McClure E. Causes of community stillbirths and early neonatal deaths in low-income countries using verbal autopsy: an international, multicenter study. J Perinatol. 2012;32(8):585.

7. Randis TM, Gelber SE, Hooven TA, Abellar RG, Akabas LH, Lewis EL, Walker LB, Byland LM, Nizet V, Ratner AJ, Group B. Streptococcus $\beta$-hemolysin/ cytolysin breaches maternal-fetal barriers to cause preterm birth and intrauterine fetal demise in vivo. J Infect Dis. 2014;210(2):265-73.

8. Waldorf KMA, Gravett MG, McAdams RM, Paolella LJ, Gough GM, Carl DJ, Bansal A, Liggitt HD, Kapur RP, Reitz FB. Choriodecidual group B streptococcal inoculation induces fetal lung injury without intra-amniotic infection and preterm labor in Macaca nemestrina. PLoS One. 2011;6(12):e28972.

9. Madhi SA, Dangor Z. Prospects for preventing infant invasive GBS disease through maternal vaccination. Vaccine. 2017

10. Lawn JE, Bianchi-Jassir F, Russell NJ, Kohli-Lynch M, Tann CJ, Hall J, Madrid L, Baker CJ, Bartlett L, Cutland C. Group B streptococcal disease worldwide for pregnant women, stillbirths, and children: why, what, and how to undertake estimates? Clin Infect Dis. 2017;65(suppl_2):S89-99.

11. Berhie KA, Gebresilassie HG. Logistic regression analysis on the determinants of stillbirth in Ethiopia. Maternal health, neonatology and perinatology. 2016;2(1):10

12. Chuwa FS, Mwanamsangu AH, Brown BG, Msuya SE, Senkoro EE, Mnali OP, Mazuguni F, Mahande MJ. Maternal and fetal risk factors for stillbirth in northern Tanzania: a registry-based retrospective cohort study. PLoS One. 2017:12(8):e0182250

13. Bhutta ZA, Das JK, Bahl R, Lawn JE, Salam RA, Paul VK, Sankar MJ, Blencowe H, Rizvi A, Chou VB. Can available interventions end preventable deaths in mothers, newborn babies, and stillbirths, and at what cost? Lancet. 2014; 384(9940):347-70.

14. Seale AC, Bianchi-Jassir F, Russell NJ, Kohli-Lynch M, Tann CJ, Hall J, Madrid $\mathrm{L}$, Blencowe $\mathrm{H}$, Cousens S, Baker CJ. Estimates of the burden of group B streptococcal disease worldwide for pregnant women, stillbirths, and children. Clin Infect Dis. 2017;65(suppl_2):S200-19.

15. Central Statistical Agency (CSA) [Ethiopia] and ICF: Ethiopia Demographic and Health Survey 2016. In. Addis Ababa, Ethiopia, and Rockville, Maryland, USA: CSA and ICF; 2016.

16. Debelew GT, Afework MF, Yalew AW. Determinants and causes of neonatal mortality in Jimma zone, Southwest Ethiopia: a multilevel analysis of prospective follow up study. PLoS One. 2014;9(9):e107184.

17. McNanley AR, Glantz JC, Hardy DJ, Vicino D. The effect of intrapartum penicillin on vaginal group B streptococcus colony counts. Am J Obstet Gynecol. 2007;197(6):583. e581-4.

18. Bailey P, Lobis S, Maine D, Fortney JA. Monitoring emergency obstetric care: a handbook: World Health Organization; 2009.

19. Getachew A, Ricca J, Cantor D, Rawlins B, Rosen H, Tekleberhan A, Bartlett L, Gibson $\mathrm{H}$. Quality of care for prevention and management of common maternal and newborn complications: a study of Ethiopia's hospitals. Baltimore: Jhpiego; 2011

20. Mgaya AH, Massawe SN, Kidanto HL, Mgaya HN. Grand multiparity: is it still a risk in pregnancy? BMC pregnancy and childbirth. 2013;13(1):241.

21. Vyas S, Kumaranayake L. Constructing socio-economic status indices: how to use principal components analysis. Health Policy Plan. 2006;21(6):459-68.

22. Cheesbrough M: District laboratory practice in tropical countries: Cambridge university press; 2006.

23. Verani JR, McGee L, Schrag SJ: Prevention of perinatal group B streptococcal disease: revised guidelines from CDC, 2010. 2010

24. Yadeta TA, Worku A, Egata G, Seyoum B, Marami D, Berhane Y. Vertical transmission of group B Streptococcus and associated factors among pregnant women: a cross-sectional study, eastern Ethiopia. Infection and drug resistance. 2018;11:397.
25. Blizzard L, Hosmer W. Parameter estimation and Goodnessâ€ of â €fit in log binomial regression. Biom J. 2006:48(1):5-22

26. Seale AC, Koech AC, Sheppard AE, Barsosio HC, Langat J, Anyango E, Mwakio S, Mwarumba S, Morpeth SC, Anampiu K. Maternal colonization with Streptococcus agalactiae and associated stillbirth and neonatal disease in coastal Kenya. Nature microbiology. 2016;1:16067.

27. Nan C, Dangor Z, Cutland C, Edwards M, Madhi S, Cunnington M. Maternal group B Streptococcus-related stillbirth: a systematic review. BJOG Int J Obstet Gynaecol. 2015;122(11):1437-45.

28. Lin F-YC, Weisman LE, Azimi P, Young AE, Chang K, Cielo M, Moyer $P$, Troendle JF, Schneerson R, Robbins JB. Assessment of intrapartum antibiotic prophylaxis for the prevention of early-onset group B streptococcal disease. Pediatr Infect Dis J. 2011:30(9):759.

29. Arnold KC, Flint CJ. Use of prophylactic antibiotics in labor and delivery. In: Obstetrics Essentials. edn: Springer; 2017. p. 129-33.

30. Nishihara Y, Dangor Z, French N, Madhi S, Heyderman R: Challenges in reducing group B Streptococcus disease in African settings. Arch Dis Child 2016:archdischild-2016-311419.

31. Madhi SA, Koen A, Cutland CL, Jose L, Govender N, Wittke F, Olugbosi M, Sobanjo-ter Meulen A, Baker S, Dull PM. Antibody kinetics and response to routine vaccinations in infants born to women who received an investigational trivalent group B Streptococcus polysaccharide CRM197conjugate vaccine during pregnancy. Clin Infect Dis. 2017;65(11):1897-904.

32. Kwatra G, Adrian PV, Shiri T, Izu A, Cutland CL, Buchmann EJ, Madhi SA. Serotype-specific cell-mediated immunity associated with clearance of homotypic group B Streptococcus rectovaginal colonization in pregnant women. J Infect Dis. 2016;213(12):1923-6.

33. Madhi SA, Cutland CL, Jose L, Koen A, Govender N, Wittke F, Olugbosi M, Sobanjo-ter Meulen A, Baker S, Dull PM. Safety and immunogenicity of an investigational maternal trivalent group B streptococcus vaccine in healthy women and their infants: a randomised phase $1 \mathrm{~b} / 2$ trial. Lancet Infect Dis. 2016;16(8):923-34

34. Kobayashi M, Vekemans J, Baker CJ, Ratner AJ, Le Doare K, Schrag SJ, Group B. Streptococcus vaccine development: present status and future considerations, with emphasis on perspectives for low and middle income countries. F1000Research. 2016;5.

35. Ashish K, Wrammert J, Ewald U, Clark RB, Gautam J, Baral G, Baral KP, Målqvist $\mathrm{M}$. Incidence of intrapartum stillbirth and associated risk factors in tertiary care setting of Nepal: a case-control study. Reprod Health. 2016;13(1):103.

36. Vornhagen J, Armistead B, Santana-Ufret V, Gendrin C, Merillat S, Coleman M, Quach P, Boldenow E, Alishetti V, Leonhard-Melief C. Group B streptococcus exploits vaginal epithelial exfoliation for ascending infection. J Clin Invest. 2018;128(5)

37. Myatt L, Muralimanoharan S, Maloyan A. Effect of preeclampsia on placental function: influence of sexual dimorphism, microRNA's and mitochondria. In: Advances in Fetal and Neonatal Physiology edn: Springer; 2014. p. 133-46.

38. Stark MJ, Dierkx L, Clifton V, Wright IM. Alterations in the maternal peripheral microvascular response in pregnancies complicated by preeclampsia and the impact of fetal sex. J Soc Gynecol Investig. 2006;13(8):573-8.

39. Gordon A, Raynes-Greenow C, McGeechan K, Morris J, Jeffery H. Risk factors for antepartum stillbirth and the influence of maternal age in New South Wales Australia: a population based study. BMC pregnancy and childbirth. 2013;13(1):12.

40. Moussa TA, Elsherif RH, Mohamed YA, Dawoud ME, AboElAref AM. Group B streptococcus colonization of pregnant women: comparative molecular and microbiological diagnosis. Comp Clin Pathol. 2013;22(6):1229-34.

41. El Aila NA, Tency I, Claeys G, Saerens B, De Backer E, Temmerman M, Verhelst R, Vaneechoutte M. Genotyping of Streptococcus agalactiae (group B streptococci) isolated from vaginal and rectal swabs of women at 35-37 weeks of pregnancy. BMC Infect Dis. 2009;9(1):153.

42. Seale AC, Blencowe H, Bianchi-Jassir F, Embleton N, Bassat Q, Ordi J, Menéndez C, Cutland C, Briner C, Berkley JA. Stillbirth with group B Streptococcus disease worldwide: systematic review and meta-analyses. Clin Infect Dis. 2017;65(suppl_2):S125-32.

43. Glass TA, Goodman SN, Hernán MA, Samet JM. Causal inference in public health. Annu Rev Public Health. 2013:34:61-75.

44. Khong TY, Mooney EE, Ariel I, Balmus NC, Boyd TK, Brundler M-A, Derricott H, Evans MJ, Faye-Petersen OM, Gillan JE. Sampling and definitions of placental lesions: Amsterdam placental workshop group consensus statement. Archives of pathology \& laboratory medicine. 2016;140(7):698-713. 